\title{
Evaluation of screening for drug use using postmortem prolactin levels in serum and cerebrospinal fluid
}

\section{N Tani, T Ikeda, Y Aoki, A Shida, S Oritani, T Ishikawa}

\begin{tabular}{|c|l|}
\hline Citation & Human \& Experimental Toxicology. 38(11); 1244-1253. \\
\hline Issue Date & 2019-11-01 \\
\hline Type & Journal Article \\
\hline Textversion & Author \\
\hline Rights & $\begin{array}{l}\text { The following article has been accepted by Human \& Experimental Toxicology Vol.38, } \\
\text { Issu.11, p.1244-1253. The final, published version is available at } \\
\text { https://doi.org/10.1177/0960327119864139. Please cite only the published version. }\end{array}$ \\
\hline DOI & $10.1177 / 0960327119864139$ \\
\hline
\end{tabular}

\author{
Self-Archiving by Author(s) \\ Placed on: Osaka City University
}


Title: Evaluation of screening for drug use using postmortem prolactin levels in serum and cerebrospinal fluid

\section{Abbreviated title: Drug screening using postmortem prolactin levels}

Authors: Naoto Tani ${ }^{1,2 *}$, Tomoya Ikeda ${ }^{1,2}$, Yayoi Aoki ${ }^{1}$, Alissa Shida ${ }^{1}$, Shigeki Oritani ${ }^{1}$, Takaki Ishikawa $^{1,2}$

${ }^{1}$ Department of Legal Medicine, Osaka City University Medical School, 1-4-3 Asahi-machi, Abeno, Osaka 545-8585, Japan

${ }^{2}$ Forensic Autopsy Section, Medico-legal Consultation and Postmortem Investigation Support Center, c/o Department of Legal Medicine, Osaka City University Medical School, 1-4-3 Asahi-machi, Abeno, Osaka 545-8585, Japan

*Corresponding author: Naoto Tani

Department of Legal Medicine, Osaka City University Medical School

1-4-3 Asahi-machi, Abeno, Osaka 545-8585, Japan

Tel: +81-6-6645-3767; Fax: +81-6-6634-3871

E-mail: tani.naoto@med.osaka-cu.ac.jp 


\section{Summary}

Prolactin (PRL) levels can usually be controlled by prolactin-inhibiting psychiatric drugs that include anti-dopamine agents. However, the use of dopamine (DA) antagonists may lead to hyperprolactinemia under certain clinical conditions. The aim of this study was to investigate postmortem PRL levels as potential markers of drug abuse, especially that of DA antagonists, in autopsy cases. We examined 121 autopsy cases, excluding cases involving acute hypoxia/ischemia, such as asphyxia, because PRL concentrations are reportedly increased under acute hypoxic conditions. Detected drugs were classified as either DA antagonists, stimulants, psychotropic drugs other than dopamine antagonists, or other non-psychotropic drugs, and many cases had no detected drugs. Samples comprised blood collected from the right heart chamber and cerebrospinal fluid (CSF). PRL protein level was measured by chemiluminescent immunoassay, and $P R L$ gene expression in the anterior pituitary of autopsy cases was analyzed by reverse transcription-polymerase chain reaction. The PRL-positive cell ratio in the anterior pituitary gland was also measured by immunohistochemical analysis. The results indicated that PRL levels in the serum and CSF were higher in DA antagonist cases than in other cases. PRL levels in the serum and CSF also correlated with the PRL gene expression in cases with abuse of DA antagonists. However, no significant difference in the PRL-positive cell ratio in the anterior pituitary gland was evident between any of the classes of drug-detected and drug-undetected cases. These results suggest that postmortem measurements of PRL transcription levels may be useful for diagnosing cases of DA antagonist use.

\section{Keywords:}

Prolactin; Dopamine antagonists; Drug screening; Gynecomastia; Forensic autopsy 


\section{Introduction}

Psychotropic drugs (e.g., sedative-hypnotic, anxiolytic, antidepressant) are often prescribed in the treatment of patients with mental disorders. ${ }^{1}$ Psychotropic drugs can improve symptoms, but various side effects have also been reported. ${ }^{2,3}$ Drugs that antagonize dopamine (DA) D2 receptors (i.e., DA antagonists) are often prescribed for schizophrenic patients, ${ }^{4}$ but the use of these DA antagonists increases prolactin (PRL) levels and can lead to hyperprolactinemia. ${ }^{5,6}$ Furthermore, prolonged hyperprolactinemia is known to lead to gynecomastia. ${ }^{7}$

PRL is a hormone primarily secreted by lactotrophs in the anterior pituitary gland. ${ }^{8} \mathrm{PRL}$ secretion is usually controlled by PRL-inhibiting factors, such as DA. ${ }^{9}$ In addition, methamphetamine fatality and other poisoning cases (e.g., with sedative-hypnotics) reportedly show increased DA levels. ${ }^{10}$ The resulting decrease in PRL levels may lead to hypoprolactinemia. ${ }^{11}$ However, no physiological studies on the effects of drugs on PRL secretion using postmortem human body fluids have been reported. Moreover, a previous immunohistochemical study suggested that clusterin-containing PRL cells in the hypophysis were increased among drug abusers and drugs may thus affect PRL secretion. ${ }^{12}$ We therefore speculated that postmortem levels of PRL in body fluids may be useful as a marker of drug abuse.

In autopsy cases, we have been conducting research and reporting on applications for identification and diagnosis of pathophysiological changes using techniques such as histopathological, toxicological, biochemical, and molecular biology examinations. Currently, detection of drugs is dependent on toxicological examinations. ${ }^{13}$ Previous studies of drug detection, especially prolonged drug detection used hair and/or nails. ${ }^{14,15}$ The aim of the present study was to clarify the feasibility of biochemical screening for drug use by measuring PRL in body fluids.

In a previous study, we reported that PRL is secreted and transported to cerebrospinal fluid (CSF) 
under hypoxic/ischemic conditions such as in cases of asphyxia. ${ }^{16}$ The present investigation of PRL levels as a potential marker for drug use therefore excluded cases of asphyxia. This study investigated PRL levels in postmortem serum and CSF. Moreover, we discuss the relationship between measurement of PRL levels in body fluids and gynecomastia in cases of drug abuse.

\section{Methods}

\subsection{Ethics statement}

This study was evaluated by the Independent Ethics Committee of the Osaka City University Graduate School of Medicine. According to the Independent Ethics Committee of the Osaka City University Graduate School of Medicine, informed consent from opt-out for the autopsy data analysis was approved (Authorization No. 4087).

\subsection{Autopsy sample}

Serial forensic autopsy cases seen within $72 \mathrm{~h}$ postmortem at our institute between 2010 and 2017 were included in this study, with the exception of putrefactive cases and cases with high destruction of the body. In the present study, only clearly accountable cases were collected, and we analyzed cases in which sufficient serum and CSF samples could be collected. In total, 121 cases (92 males, 29 females) were included. Median age was 61.0 years (range, 1-95 years), and median survival period was $0.5 \mathrm{~h}$ (range, $0.5-240 \mathrm{~h}$ ) (Table 1). For the present examination, survival was established based on witnessed and circumstantial evidence, and postmortem period was estimated based on pathological findings. ${ }^{17}$ Specimens were collected aseptically using syringes to obtain blood from the right heart chambers and CSF. Blood samples were subsequently stored at $-20{ }^{\circ} \mathrm{C}$ until use. 


\subsection{Toxicological analyses}

Blood $\mathrm{CO}-\mathrm{Hb}$ saturation (\%) was analyzed using a CO-oximeter system (ABL 80 FLEX system, Radiometer, Copenhagen, Denmark). ${ }^{18,19}$ Blood alcohol levels were determined using headspace gas chromatography/mass spectrometry (GC/MS). ${ }^{20}$

For GC/MS, a 0.5-ml aliquot of sample was used. Automated GC/MS following solid/liquid phase extraction was performed using an Agilent Technologies GC/MS System Model 5975c MSD (column, DB-5MS, $30 \mathrm{~m} \times 0.25 \mathrm{~mm}$ i.d.; film, $0.25 \mu \mathrm{m}$; column temperature, $100-325{ }^{\circ} \mathrm{C}$; injector temperature, $280{ }^{\circ} \mathrm{C}$; turbocharged carrier gas, He at a flow rate of $48 \mathrm{ml} / \mathrm{s}$; interface temperature, $300{ }^{\circ} \mathrm{C}$ ). Quantitative analytical precision was less than $10 \%$ for all drugs in each specimen.

\subsection{Computed tomography (CT) analysis}

Evaluation of gynecomastia using CT was performed for 58 male cases, comprising all males except those cases involving severe burns, chest injury and sternal fracture accompanying cardiopulmonary resuscitation. Postmortem CT was performed immediately before autopsy within the framework of routine casework using a CT scanner (ECLOS; Hitachi Medical, Tokyo, Japan; $120 \mathrm{kVp}, 200 \mathrm{mAs}, 1.25$ pitch factor, $1.25 \times 16 \mathrm{~mm}$ collimation, and 1.25 -mm section thickness). A CT image-analyzing system (Volume Analyzer SYNAPSE VINCENT version 3; FUJIFILM Medical, Tokyo, Japan) was used for image analysis. Thickness and width of mammary gland-like tissue under the nipple was measured manually (in millimeters). Development of the mammary gland was mainly used for classification of gynecomastia. The classification systems described breast size as positive or negative due to categorization of combined tissue types, with reference to previous reports. ${ }^{21,22}$ We checked postmortem CT images of breast sections using Fat Pointer ${ }^{\circledR}$ (Hitachi Medical) to show subcutaneous fat and mammary gland (distribution of CT attenuation values in fat tissue: -50 to -201 Hounsfield units). 


\subsection{Biochemical analysis}

Amounts of PRL in serum and CSF were measured by chemiluminescent enzyme immunoassay using PATHFAST ${ }^{\circledR}$ (LSI Medience, Tokyo, Japan) according to the protocol provided by the manufacturer. For these measurements, the clinical serum reference range was $4.98-26.4 \mathrm{ng} / \mathrm{mL}$ for males and 1.74-26.8 $\mathrm{ng} / \mathrm{mL}$ for females. DA levels in serum from right heart blood and in CSF were measured by automated analyzer comprising high-performance liquid chromatography-tandem mass spectrometry (HPLC/MS/MS) and electrochemical detection (HLC-8030; Toso, Tokyo, Japan). ${ }^{23,24}$ Solid-phase extraction (SPE) or online SPE coupled with the HPLC/MS/MS approach was used to provide a sensitive, specific alternative for the quantification of DA in plasma. Stock solutions of DA were prepared at $0.05 \mathrm{mg} / \mathrm{mL}$ of the base by dissolving the dry chemical or its salt in $0.1-\mathrm{N} \mathrm{HCl}$. Dilution to the working concentration of $0.5 \mu \mathrm{L}$ was achieved by volumetrically diluting $1 \mathrm{~mL}$ of the stock to $100 \mathrm{~mL}$ with $0.1-\mathrm{N} \mathrm{HCl}$. Finally, the injection standard analyzed on the HPLC for the purpose of calculating the results was created with a final volumetric dilution, adding $5 \mathrm{~mL}$ of each DA working solution and filling to $100 \mathrm{~mL}$ with $0.1 \mathrm{~mL}$ of $0.1-\mathrm{N} \mathrm{HCl}$. The injection standard had a final concentration of $2.5 \mu \mathrm{g} / \mathrm{mL}$; when injected into the $20-\mu \mathrm{L}$ loop of HPLC, this would result in injection of $50 \mathrm{ng}$ of DA. The order of elution from the column for each DA in the injection standard was consistent, and tracked by regular injection.

Plasma samples were extracted with an internal standard of 2,3-dihydroxybenzonic acid (DHBA), which was prepared using a 1-mL working solution of DHBA volumetrically diluted to $10 \mathrm{~mL}$ with $0.1 \mathrm{~mL}$ of $0.1-\mathrm{N} \mathrm{HCl}$ to achieve a concentration of $50 \mathrm{ng} / \mathrm{mL}$. The recovery of the DHBA internal standard within sample extractions was $60 \%$ on average.

The clinical serum reference range for DA in peripheral venous blood was $<20 \mathrm{pg} / \mathrm{ml}$. Serum samples were diluted between 10- and 1,000-fold with saline before measurement. The accuracy 
and reliability of tests were confirmed for reproducibility with 10 serial dilutions, and non-reproducible data were not considered.

\subsection{Quantification of $m R N A$ in the pituitary gland}

Pituitary gland tissue specimens were immediately immersed in $1 \mathrm{~mL}$ of RNA stabilization solution (RNAlater ${ }^{\mathrm{TM}}$; Ambion, Austin, TX), and measurements were made as soon as possible. Total RNA was isolated using Isogen (Nippon Gene, Toyama, Japan) according to the instructions from the manufacturer. A high-capacity RNA-to-cDNA kit (Applied Biosystems, Foster City, CA) was used to synthesize cDNA copies of total RNA. The reaction mixture included $9-\mu \mathrm{L}$ samples of total RNA, $10.0 \mu \mathrm{L}$ of $2 \times \mathrm{RT}$ buffer, and $1.0 \mu \mathrm{L}$ of $20 \times \mathrm{RT}$ enzyme mix. Conditions for reverse transcription were as follows: $37^{\circ} \mathrm{C}$ for $60 \mathrm{~min}$ and $95^{\circ} \mathrm{C}$ for $5 \mathrm{~min}$. A total of $20.0 \mu \mathrm{L}$ of reaction mixture containing 10.0 $\mu \mathrm{L}$ TaqMan ${ }^{\circledR}$ gene expression master mix $(2 \times), 1.0 \mu \mathrm{L}$ TaqMan ${ }^{\circledR}$ gene expression assay (20×), $4 \mu \mathrm{L}$ cDNA, and $5 \mu \mathrm{L} \mathrm{H}_{2} \mathrm{O}$ were added to each well of a Fast 96-well reaction plate $(0.1 \mathrm{~mL})$. Quantitative reverse transcription polymerase chain reaction (PCR) was performed using primers for PRL (TaqMan assay ID: Hs00168730_m1) on a StepOnePlus real-time PCR system (Applied Biosystems). The threshold cycle (Ct) was calculated automatically by the instrument software with a threshold value of 0.2 . The stability of endogenous reference genes in the pituitary gland was tested. For this study, the endogenous reference gene used was SDHA (TaqMan assay ID: Hs00188166_m1), which was the most stable of the endogenous reference

genes analyzed (Actin $\beta, B 2 M, G A P D H, H M B S, H P R T 1, P P I A, S D H A$, and TBP) ${ }^{25,26} \operatorname{TaqMan}^{\circledR}$ Gene Expression Assays were purchased from Applied Biosystems and tested according to the protocol from the manufacturer.

\subsection{Immunohistochemistry}


Serial $4-\mu \mathrm{m}$ sections were prepared from formalin-fixed, paraffin-embedded tissue specimens obtained from the pituitary. Rabbit polyclonal antibody to PRL (ab64377; Abcam) was used at empirically determined dilutions. Immunoreactivity was achieved by the polymer method using Dako EnVision+ Dual Link System-HRP (K4063; Dako, CA, USA) and Dako Liquid DAB+ Substrate Chromogen System (K3468; Dako) according to the instructions from the manufacturer. Percent positivity in the pituitary was estimated as the percentage of positive PRL cells, which was calculated as follows: number of positive PRL cells / total number of anterior pituitary cells $\times 100$.

\subsection{Statistical analysis}

Pearson's and Spearman's rank correlation coefficient were used to compare two values, including PRL levels, DA levels, age of subjects, postmortem period, and survival period. For comparisons between groups, we used the nonparametric Mann-Whitney U test. The Kruskal-Wallis test was used for analyses involving multiple comparisons. In this test, the line in each box represents the median, and lines outside each box indicate the $90 \%$ confidence interval. Maximum PRL and DA levels in serum and CSF were log-transformed for graphical presentation only. Diagnostic relevance was estimated according to the values obtained for sensitivity, specificity, and accuracy (proportion of subjects correctly predicted). Youden's index (sensitivity + specificity -1 ) was used to determine the optimal cut-off. The results are presented as medians. All analyses were performed using SPSS version 9.0 statistical package (SPSS, Chicago, IL). Values of $p<0.05$ were considered significant.

\section{Results}

\subsection{Detected drugs and classification}

Detected drugs were classified on a routine toxicological basis, as shown in Table 1. Detailed 
information on detected drugs is shown in Table 2.

\subsection{Evaluation of gynecomastia using CT}

As a result of sing CT analysis, no gynecomastia was observed in the present study. Mammary width in 58 measurable males was $3.8 \mathrm{~mm} \sim 82.3 \mathrm{~mm}$ (left: $3.8 \mathrm{~mm}-82.3 \mathrm{~mm}$; right: $4.0 \mathrm{~mm}-71.8$ $\mathrm{mm})$. Further, mammary gland was unchanged by presence of DA antagonists or PRL level. On the other hand, a negative correlation was observed between DA level and area of mammary gland-like tissue (left: $r=-0.365, p<0.01$; right: $r=-0.394, p<0.01$ ).

\subsection{Biochemical analysis of PRL level for drug screening}

\subsubsection{Relationships with sex, age, survival period, postmortem period and sampling site}

Serum PRL levels were lower in males than in females (male: median, $19.0 \mathrm{ng} / \mathrm{mL}$; range, 1.99-217 ng/mL; female: median, $26.3 \mathrm{ng} / \mathrm{mL}$; range, 7.05-200 ng/mL) (p < 0.01). PRL levels in CSF and PRL $m R N A$ expression showed no difference by sex. No correlations were identified between PRL levels in serum and CSF and either age or survival period. Weak correlations were evident between postmortem period and PRL levels in serum and CSF (serum: $r=-0.209, p<0.05$; CSF: $r=-0.219, p<0.05)$. A weak correlation was observed between serum and CSF levels of PRL $(\mathrm{r}=0.219, \mathrm{p}<0.05)$. PRL level was significantly higher in serum (median, $22.4 \mathrm{ng} / \mathrm{mL}$; range, 1.99-217 ng/mL) than in CSF (median, $11.4 \mathrm{ng} / \mathrm{mL}$; range, $1.23-394 \mathrm{ng} / \mathrm{mL} ; \mathrm{p}<0.001$ ).

\subsubsection{Relationship to classification of detected drugs}

Serum PRL levels in the present cases except DA antagonist cases were similar to the clinical reference levels, and higher in some cases. Serum and CSF PRL levels were higher in the DA antagonist cases (serum, 18.8-200 ng/mL; median, $41.0 \mathrm{ng} / \mathrm{mL}$; CSF: 11.7-394 ng/mL; median, 
$34.1 \mathrm{ng} / \mathrm{mL}$ ) than in other cases (serum: 1.99-217 ng/mL; median, $20.3 \mathrm{ng} / \mathrm{mL}$; CSF: $1.23-97.2$ $\mathrm{ng} / \mathrm{mL}$; median, $9.26 \mathrm{ng} / \mathrm{mL})(p<0.01-p<0.05)$. Multiple comparisons showed that PRL levels in serum were higher in DA antagonist cases than in other cases $(p<0.01-p<0.05)$ (Fig. 1a). PRL levels in CSF were higher in the DA antagonist cases than in other cases $(p<0.01-p<0.05)$ (Fig. 1b) (Table 3). Cut-off values of $33.6 \mathrm{ng} / \mathrm{mL}$ for serum samples (sensitivity, 0.700 ; specificity, 0.784 ) and $16.6 \mathrm{ng} / \mathrm{mL}$ for CSF samples (sensitivity, 0.900; specificity, 0.667) were identified to distinguish higher and lower PRL levels (DA antagonists vs. other groups). On the other hand, no significant differences in serum and CSF levels of DA were apparent between drug-detected cases and drug-undetected cases (Fig. 2; Table 3). Moreover, no correlation was seen in serum and CSF between DA levels and PRL levels $(p>0.05)$.

No relationship was identified between serum, CSF or mRNA expression of PRL levels and blood alcohol levels.

\subsection{Relative quantification of PRL mRNA levels in pituitary gland with regard to detected drugs}

$P R L$ expression was slightly negatively correlated with age $(r=-0.346, p<0.001)$ and survival period $(r=-0.221, p<0.01)$. Significant differences in $P R L$ gene expression in the pituitary were seen between DA antagonist cases and other cases $(p<0.01)$ (Fig. 1c). As a result of multiple comparisons, $P R L$ gene expression were higher in DA antagonist cases than in other groups, except for stimulant cases $(p<0.05-0.01)$. PRL expression was weakly associated with serum and CSF PRL levels (serum: $r=0.186, p<0.05$; CSF: $r=0.214, p<0.05$ ). In particular, $P R L$ expression correlated with serum and CSF PRL levels in DA antagonist cases (serum: $r=0.733, p<0.05$; CSF: $r=0.855, p<0.01)($ Fig. 3).

\subsection{Immunohistochemical PRL-positivity ratio}


No significant difference in the PRL-positivity ratio in the anterior pituitary gland was identified between drug-detected cases and drug-undetected cases. PRL-positive ratios were: DA antagonists (median, 22\%; range, 13-62\%), stimulants (median, 16\%; range, 11-43\%), psychotropic drugs except for dopamine antagonists (median, 19\%; range, 4-56\%), other non-psychotropic drugs (median, 22\%; range, 1-61\%), and no detected drugs (median, 24\%; range, 5-55\%) (Figs. 4 and 5).

\section{Discussion}

Evaluations of gynecomastia in drug users were conducted using image analyses of CT data. However, gynecomastia was not observed in any cases of drug-use autopsy, including DA antagonist cases. No differences were observed between serum, CSF, mRNA PRL levels and the thickness and width of the mammary gland-like tissue under the nipple. On the other hand, a negative correlation was observed between DA levels and width of mammary gland-like tissue. These results suggested that decreased DA levels, rather than increased PRL levels, may be related to gynecomastia. Several studies have reported on the diagnosis of gynecomastia, but the diagnosis is often made by visual inspection. ${ }^{22}$ However, in forensic autopsy and postmortem CT analysis, individual differences such as body type are large, and gynecomastia can be difficult to diagnose. Therefore, it was difficult to determine the period of the drug use in the gynecomastia as an index.

In the present study, since both serum and CSF PRL levels were higher in DA antagonist cases than in other cases, DA antagonist users have shown hyperprolactinemia. Serum PRL levels in the present cases other than DA antagonist cases were similar to the clinical reference level, including some higher cases. Serum PRL levels $>20 \mathrm{ng} / \mathrm{mL}$ can reportedly be found in clinical cases with hyperprolactinemia. ${ }^{27}$ Serum median PRL level in DA antagonist cases was $41.0 \mathrm{ng} / \mathrm{ml}$ in our study, and such PRL levels were within the diagnostic range for hyperprolactinemia. Cut-off values of $33.6 \mathrm{ng} / \mathrm{mL}$ for serum level, and the new result of $16.6 \mathrm{ng} / \mathrm{mL}$ for CSF level (not based on clinical 
data) were identified to distinguish hyperprolactinemia in autopsy cases. These results suggested that measurement of PRL levels would be useful in biochemical analysis for drug screening. On the other hand, stimulant cases showed a median $9.14 \mathrm{ng} / \mathrm{ml}$, representing low PRL levels. This might be related to DA levels due to use of stimulants in clinical cases. Stimulant drugs have previously been reported to be associated with non-significant tendencies toward reductions in PRL secretion. ${ }^{28,29}$ However, in the present cases, serum and CSF DA levels did not differ among classifications of detected kind of the drugs.

Generally, instrumental analyses including GC/MS and LC/MS/MS are used for drug analyses, including qualitative and quantitative analyses. ${ }^{30}$ Compared to our examinations, drug analysis using biochemical analysis can be performed quickly by simple processing during the clinical practice of measuring useful biochemical markers. ${ }^{31}$ Furthermore, as a future perspective, focusing on other specific classes of drugs and analyzing biochemical markers is expected to further enhance the utility of drug screening by biochemical analysis.

In terms of the mechanism of PRL production for each detected drug, $P R L$ expression was significantly higher in DA antagonist cases than in other causes of death, and correlated with serum and CSF PRL levels. In particular, $P R L$ expression correlated strongly with serum $(\mathrm{r}=0.733)$ and CSF $(r=0.855)$ PRL levels in DA antagonist cases. These results suggested that PRL secretion depending on $P R L$ expression is stimulated by the inhibition of DA in DA antagonist cases. Moreover, $P R L$ expression in the pituitary gland showed a slight negative correlation with serum DA levels. This suggested that $P R L$ expression was inhibited by serum DA. Both serum and CSF PRL levels were increased in DA antagonist cases, but stimulant cases showed decreased serum levels of PRL. Our previous study reported that PRL selectively transported to CSF from blood under hypoxic/ischemic conditions. ${ }^{16}$ Methamphetamine reportedly alters the dopaminergic system and damages the blood-brain barrier (BBB), the structure that protects brain tissue from substances 
circulating in the blood. ${ }^{32}$ A previous study investigated intermittent hypoxia on DA release in rat brain treated with amphetamine. The stimulatory effect of hypoxia on plasma PRL was attenuated in the presence of amphetamine. ${ }^{33}$ These results suggest that stimulant case may be under similar conditions to systemic hypoxia/ischemia.

Some limitations may be considered in this study. This study sought to investigate PRL levels in postmortem serum and CSF as potential markers of drug abuse in forensic autopsy cases. Previous papers have reported hair analysis using GC/MS and LC/MS as one of the most efficient tools for investigating drug-related history. ${ }^{34,35}$ However, we could not identify individual effects of the kind of drug on PRL secretion, because the number of cases with DA antagonists was insufficient. Moreover, since we could not identify the period of drug use from autopsy, distinguishing between chronic users and temporary users was difficult.

\section{Conclusion}

In conclusion, the use of dopamine antagonists increased PRL levels in both serum and CSF. Gene expression analysis of $P R L$ suggested that PRL levels in serum and CSF were controlled by $P R L$ gene expression. These results suggested that postmortem measurements of PRL can be useful in screening for use of DA antagonists. Furthermore, focusing on other drugs and analyzing biochemical markers are expected to further increase the usefulness of biochemical analysis in drug screening. In addition, PRL may be useful not only in the forensic field, but also in the clinical practice of conducting biochemical analyses.

\section{Conflict of Interest}

The authors declare no conflicts of interest. 


\section{Funding}

This research did not receive any specific grant from funding agencies in the public, commercial, or not-for-profit sectors.

\section{Data Availability}

All data generated or analysed during this study are included in this published article and its supplementary information files.

\section{References}

1. Carrier F, Banayan D, Boley R, et al. Ethical challenges in developing drugs for psychiatric disorders. Prog Neurobiol. 2017; 152: 58-69.

2. Montejo AL, Montejo L and Baldwin DS. The impact of severe mental disorders and psychotropic medications on sexual health and its implications for clinical management. World Psychiatry. 2018; 17: 3-11.

3. Takechi K, Yoshioka Y, Kawazoe H, et al. Psychiatric Patients with Antipsychotic Drug-Induced Hyperprolactinemia and Menstruation Disorders. Biol Pharm Bull. 2017; 40: $1775-1778$.

4. Delcourte S, Ashby CR Jr, Rovera R, et al. The novel atypical antipsychotic cariprazine demonstrates dopamine D2 receptor-dependent partial agonist actions on rat mesencephalic dopamine neuronal activity. CNS Neurosci Ther. 2018; 24: 1129-1139.

5. Chang A and Shin SH. Dopamine agonists both stimulate and inhibit prolactin release in GH4ZR7 cells. Eur J Endocrinol. 1999; 141: 387-395. 
6. Majumdar A and Mangal NS. Hyperprolactinemia. J Hum Reprod Sci. 2013; 6: 168-175.

7. Tewksbury A and Olander A. Management of antipsychotic-induced hyperprolactinemia. Ment Health Clin. 2016; 6: 185-190.

8. Cabrera-Reyes EA, Limón-Morales O, Rivero-Segura NA, et al. Prolactin function and putative expression in the brain. Endocrine. 2017; 57: 199-213.

9. Gragnoli C, Reeves GM, Reazer J, et al. Dopamine-prolactin pathway potentially contributes to the schizophrenia and type 2 diabetes comorbidity. Transl Psychiatry. 2016; 6: e785.

10. Zhu BL, Ishikawa T, Michiue T, et al. Postmortem serum catecholamine levels in relation to the cause of death. Forensic Sci Int. 2007; 173: 122-129.

11. Rastrelli G, Corona G and Maggi M. The role of prolactin in andrology: what is new? Rev Endocr Metab Disord. 2015; 16: 233-248.

12. Ishikawa $\mathrm{T}, \mathrm{Zhu} \mathrm{BL}$, Miyaishi $\mathrm{S}$, et al. Increase in clusterin-containing follicles in the adenohypophysis of drug abusers. Int J Legal Med. 2007; 121: 395-402.

13. Maeda H, Ishikawa $\mathrm{T}$ and Michiue $\mathrm{T}$. Forensic biochemistry for functional investigation of death: concept and practical application. Leg Med (Tokyo). 2011; 13: 55-67.

14. Di Corcia D, Salomone A and Gerace E. Analysis of Drugs of Abuse in Hair Samples by Ultrahigh-Performance Liquid Chromatography-Tandem Mass Spectrometry (UHPLC-MS/MS). Methods Mol Biol. 2018; 1810: 107-114.

15. Krumbiegel F, Hastedt M, Westendorf L, et al. The use of nails as an alternative matrix for the long-term detection of previous drug intake: validation of sensitive UHPLC-MS/MS methods for the quantification of 76 substances and comparison of analytical results for drugs in nail and hair samples. Forensic Sci Med Pathol. 2016; 12: 416-434.

16. Tani N, Ikeda T, Watanabe M, et al. Prolactin selectively transported to cerebrospinal fluid from blood under hypoxic/ischemic conditions. PLoS One. 2018; 13: e0198673. 
17. Tani N, Ikeda T, Oritani S, et al. Role of Circadian Clock Genes in Sudden Cardiac Death: A Pilot Study. J Hard Tissue Biol. 2017; 26: 347-354.

18. Maeda H, Fukita K, Oritani S, et al. Evaluation of post-mortem oxymetry with reference to the causes of death. Forensic Sci Int. 1997; 87: 201-210.

19. Oritani S, Zhu BL, Ishida K, et al. Automated determination of carboxyhemoglobin contents in autopsy materials using head-space gas chromatography/mass spectrometry. Forensic Sci Int. 2000; 113: 375-379.

20. Maeda H, Zhu BL, Ishikawa T, et al. Evaluation of post-mortem ethanol concentrations in pericardial fluid and bone marrow aspirate. Forensic Sci Int. 2006; 161: 141-143.

21. Çil Y, Babayiğit MA, Aktaş G, et al. Adipose tissue measurement in gynecomastia with computerized tomography. Erciyes Med J. 2012; 34: 15-19.

22. Waltho D, Hatchell A and Thoma A. Gynecomastia Classification for Surgical Management: A Systematic Review and Novel Classification System. Plast Reconstr Surg. 2017; 139: $638 \mathrm{e}-648 \mathrm{e}$.

23. Nishiyama T. Hemodynamic and catecholamine response to a rapid increase in isoflurane or sevoflurane concentration during a maintenance phase of anesthesia in humans. J Anesth. 2005; 19: $213-217$.

24. Kambayashi J, Shinoki N, Nakamura T, et al. Prevalence of impaired responsiveness to epinephrine in platelets among Japanese. Thromb Res. 1996; 81: 85-90.

25. Wang Q, Ishikawa T, Michiue T, et al. Stability of endogenous reference genes in postmortem human brains for normalization of quantitative real-time PCR data: comprehensive evaluation using geNorm, NormFinder, and BestKeeper. Int J Legal Med. 2012; 126: 943-952.

26. Huth A, Vennemann B, Fracasso T, et al. Apparent versus true gene expression changes of three hypoxia-related genes in autopsy derived tissue and the importance of normalization. Int $J$ 
Legal Med. 2013; 127: 335-344.

27. Serri O, Chik CL, Ur E, et al. Diagnosis and management of hyperprolactinemia. CMAJ. 2003; 169: $575-581$.

28. Schmid Y, Hysek CM, Simmler LD, et al. Differential effects of MDMA and methylphenidate on social cognition. J Psychopharmacol. 2014; 28: 847-856.

29. Zorick T, Mandelkern MA, Lee B, et al. Elevated plasma prolactin in abstinent methamphetamine-dependent subjects. Am J Drug Alcohol Abuse. 2011; 37: 62-67.

30. Tominaga M, Michiue T, Inamori-Kawamoto O, et al. Efficacy of drug screening in forensic autopsy: retrospective investigation of routine toxicological findings. Leg Med (Tokyo). 2015; 17: $172-176$.

31. Maeda H, Zhu BL, Ishikawa T, et al. Significance of postmortem biochemistry in determining the cause of death. Leg Med (Tokyo). 2009; 11 Suppl 1: S46-49.

32. Rosas-Hernandez H, Cuevas E, Lantz SM, et al. Prolactin protects against the methamphetamine-induced cerebral vascular toxicity. Curr Neurovasc Res. 2013; 10: 346-355.

33. Yu PL, Cheng SY, Chou JC, et al. Regulation of Intermittent Hypoxia on Brain Dopamine in Amphetaminized Rats. Chin J Physiol. 2015; 58: 219-227.

34. Kyriakou C, Pellegrini M, García-Algar O, et al. Recent Trends in Analytical Methods to Determine New Psychoactive Substances in Hair. Curr Neuropharmacol. 2017; 15: 663-681.

35. El-Nahhal Y, El-Dahdouh N, Hamdona N, et al. Toxicological data of some antibiotics and pesticides to fish, mosquitoes, cyanobacterial mats and to plants. Data Brief. 2016; 6: 871-880. 


\section{Figure legends}

Fig. 1. Serum, CSF, and $m R N A P R L$ levels regarding classification of detected drugs.

a) Serum PRL levels were higher in DA antagonist cases than in other cases $(p<0.05)$. Significantly higher: DA antagonists vs. stimulants $(p<0.01)$. b) CSF PRL levels were higher in DA antagonist cases than in other cases $(p<0.05)$. Significantly higher: DA antagonists vs. no detected drugs $(p<0.01)$. c) $m R N A P R L$ levels in the anterior pituitary gland were higher in the dopamine antagonist cases than in other cases $(p<0.05)$. Significantly higher: DA antagonists vs. psychotropic drugs except for DA antagonists, other non-psychotropic drugs $(p<0.01)$.

$\mathbf{a}$

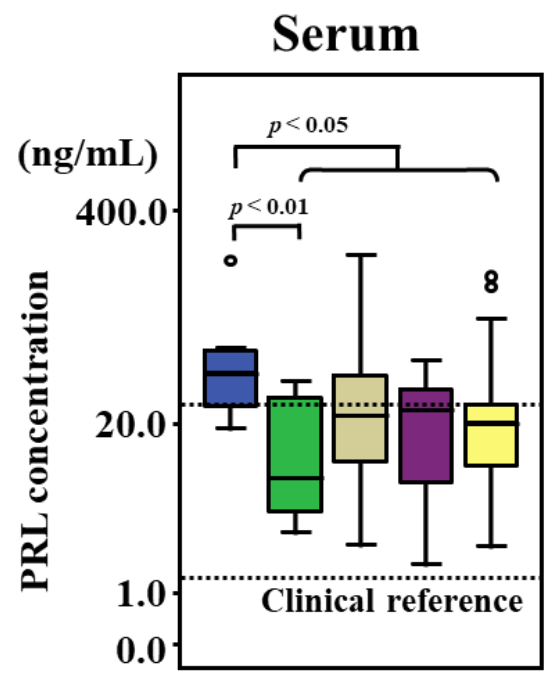

Dopamine antagonists

$\square$ Other non-psychotropic drugs b

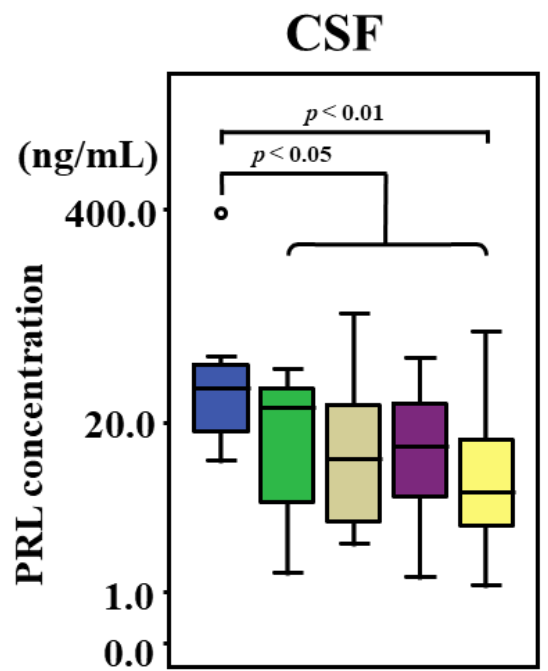

Stimulants

No detected drugs

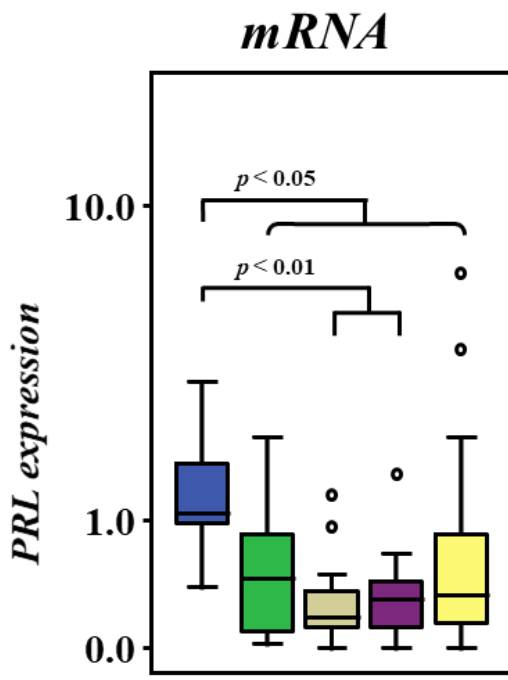

Psychotropic drugs except for dopamine antagonists 
Fig. 2. Serum and CSF DA levels regarding classification of detected drugs. No significant difference in DA level is apparent between drug-detected cases and drug-undetected cases.

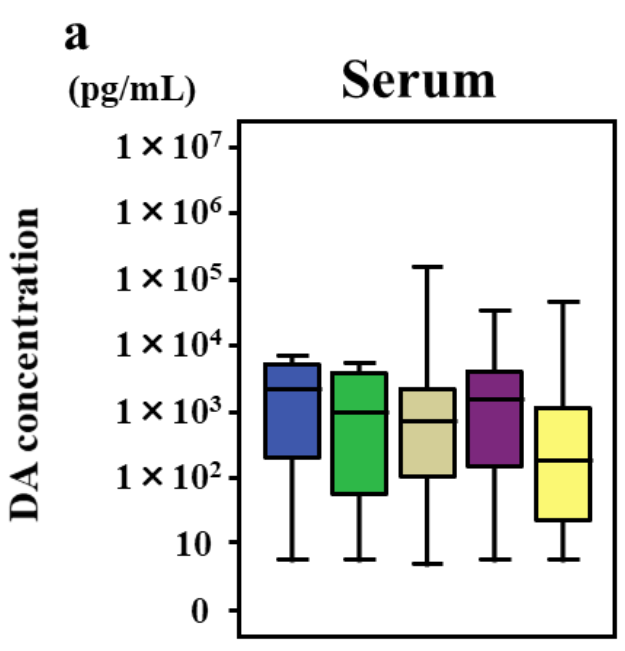

Dopamine antagonists

$\square$ Other non-psychotropic drugs
Stimulants No detected drugs

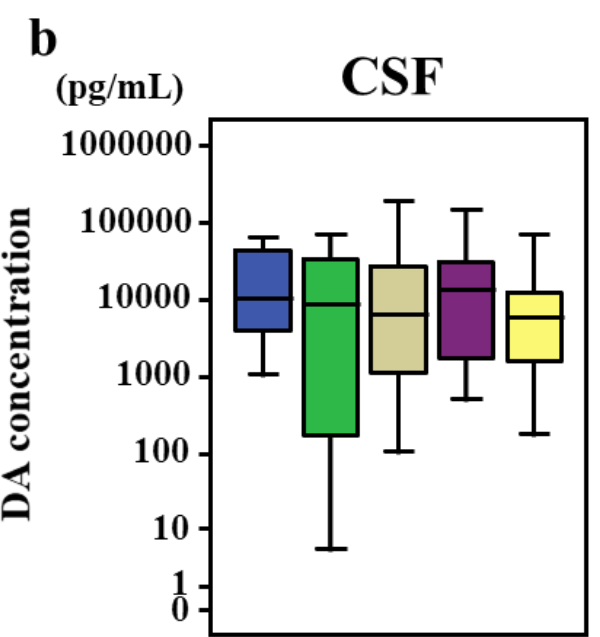

$\square$ Psychotropic drugs except for dopamine antagonists 
Fig. 3. Relationships between quantification of $m R N A$ PRL levels in the anterior pituitary gland and serum and CSF levels of PRL.

Positive correlations are apparent, particularly for the association of $P R L$ expression with serum (a) and CSF (b) PRL levels in DA antagonist cases (serum: $r=0.733, p<0.05$; CSF: $r=0.855, p<$ $0.01)$.

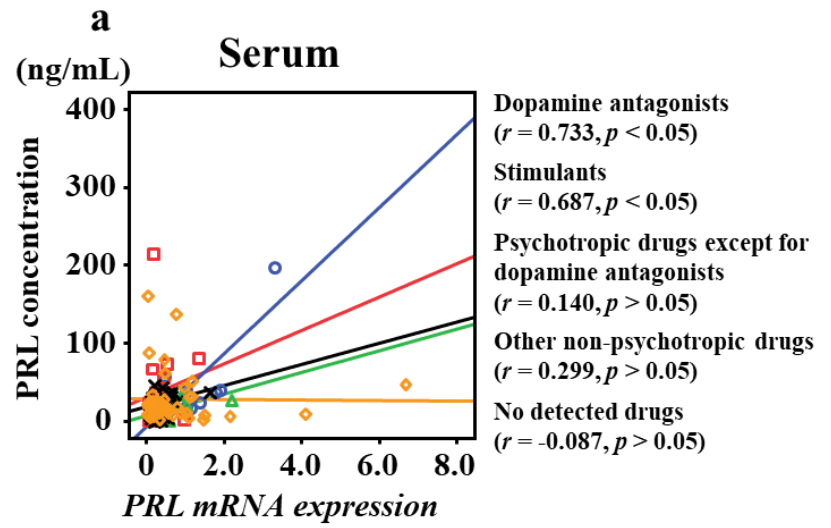

O Dopamine antagonists

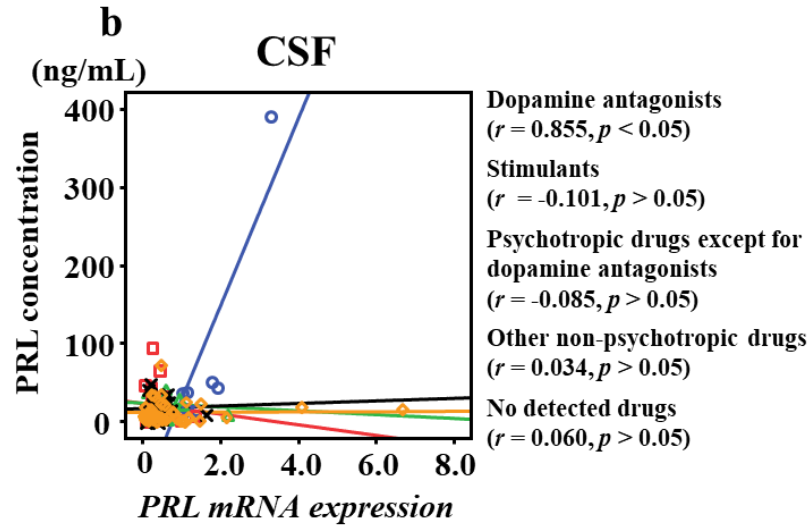

$\square$ Psychotropic drugs except for dopamine antagonists 
Fig. 4. Immunostaining for PRL in the anterior pituitary gland in cases of DA antagonists (a), stimulant cases (b), and no detected cases (c). Immunostaining results did not show any significant difference (magnification $\times 200)$. Bar $=50 \mu \mathrm{m}$.

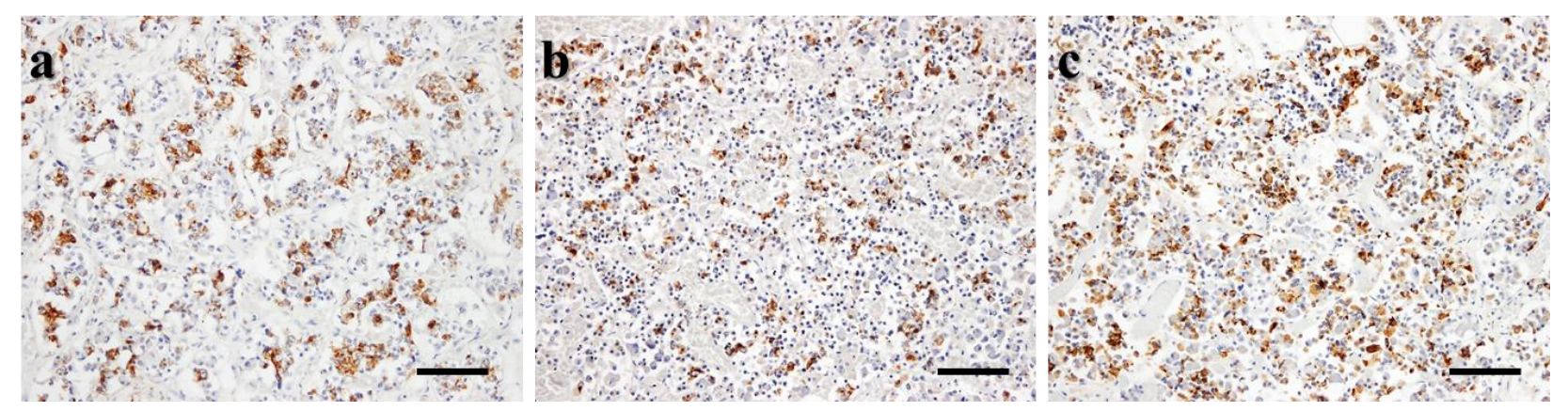


Fig. 5. Immunohistochemical PRL-positivity ratio regarding classification of detected drugs.

No significant difference in PRL-positivity ratio in the anterior pituitary gland is evident between drug-detected and drug-undetected cases.

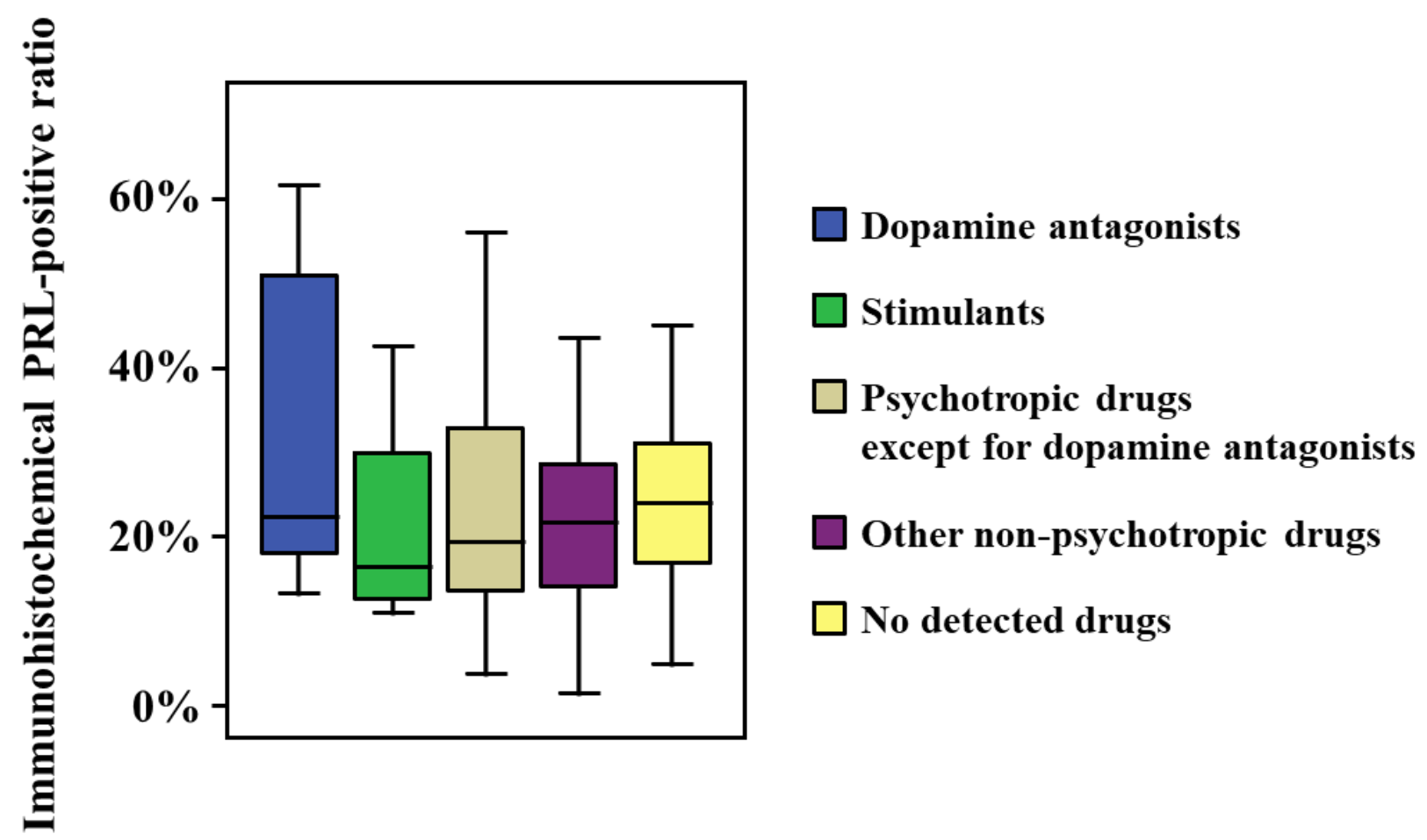




\section{Table legends}

Table 1. Case profiles of classifications of detected drugs.

\begin{tabular}{|c|c|c|c|c|c|c|c|c|c|}
\hline \multirow{2}{*}{ Classifications of the detected drugs } & \multirow{2}{*}{$\mathrm{n}$} & \multirow{2}{*}{$\begin{array}{l}\text { Male/ } \\
\text { female }\end{array}$} & \multicolumn{2}{|c|}{ Age (years) } & \multicolumn{2}{|c|}{ Survival period (h) } & \multicolumn{2}{|c|}{ Postmortem period (h) } & \multirow{2}{*}{$\begin{array}{c}\text { Hospitalization } \\
\text { (yes/no) }\end{array}$} \\
\hline & & & Range & Median & Range & Median & Range & Median & \\
\hline Dopamine antagonists & 10 & $5 / 5$ & $32-61$ & 44.5 & $0.5-24$ & 5.5 & $10-55$ & 39 & $3 / 7$ \\
\hline Stimulants & 10 & $7 / 3$ & $25-60$ & 41.5 & $0.5-144$ & 2 & $16-61$ & 35 & $2 / 8$ \\
\hline $\begin{array}{l}\text { Psychotropic drugs } \\
\text { except for dopamine antagonists }\end{array}$ & 23 & $19 / 4$ & $1-95$ & 59 & $0.5-240$ & 13 & $7-69$ & 23 & $16 / 7$ \\
\hline Other non-psychotropic drugs & 28 & $20 / 8$ & $21-84$ & 61 & $0.5-30$ & 1.5 & $6-56$ & 21 & $17 / 11$ \\
\hline No detected drugs & 50 & $41 / 9$ & $20-91$ & 72 & $0.5-1$ & 0.5 & $8-64$ & 24 & $1 / 49$ \\
\hline Total & 121 & $92 / 29$ & $1-95$ & 61 & $0.5-240$ & 0.5 & $6-64$ & 25 & $39 / 82$ \\
\hline
\end{tabular}


Table 2. Detected classification drugs and drug concentrations.

\begin{tabular}{|c|c|c|c|}
\hline Detected drugs & & $\mathrm{n}$ & Concentration range (median) $(\mu \mathrm{g} / \mathrm{mL})$ \\
\hline \multirow[t]{3}{*}{ Dopamine antagonists } & Chlorpromazine & 5 & $0.005-1098(0.167)$ \\
\hline & Levomepromazine & 3 & $1.163-2.180(1.212)$ \\
\hline & Olanzapine & 4 & $0.629-9.690(3.761)$ \\
\hline \multirow[t]{2}{*}{ Stimulants } & Amphetamine & 12 & $0.010-1.200(0.106)$ \\
\hline & Methamphetamine & 12 & $0.010-3.695(1.039)$ \\
\hline \multirow{14}{*}{$\begin{array}{l}\text { Psychotropic drugs except for } \\
\text { dopamine antagonists }\end{array}$} & Amitriptyline & 1 & $0.019(-)$ \\
\hline & Amobarbital & 1 & $29.684(-)$ \\
\hline & Carbamazepine & 1 & $4.475(-)$ \\
\hline & Desipramine & 1 & $0.004(-)$ \\
\hline & Diazepam & 5 & $0.023-0.445(0.072)$ \\
\hline & Dothiepin & 1 & $0.001(-)$ \\
\hline & Estazolam & 2 & $0.044-0.109(0.765)$ \\
\hline & Flunitrazepam & 2 & $0.288-0.650(0.469)$ \\
\hline & Midazolam & 8 & $0.013-1.826(0.486)$ \\
\hline & Mirtazapine & 2 & $0.013-0.326(0.169)$ \\
\hline & Phenobarbital & 14 & $0.002-27.611(5.197)$ \\
\hline & Promethazine & 9 & $0.015-1.528(0.210)$ \\
\hline & Secobarbital & 2 & $0.175-2.246(1.210)$ \\
\hline & Zolpidem & 4 & $0.005-0.172(0.019)$ \\
\hline \multirow[t]{13}{*}{ Other non-psychotropic drugs } & Acetaminophen & 2 & $0.240-0.440(0.340)$ \\
\hline & Aminopyrine & 1 & $0.019(-)$ \\
\hline & Chlorpheniramine & 3 & $0.025-2.434(0.847)$ \\
\hline & Dihydrocodeine & 2 & $0.023-1.773(0.898)$ \\
\hline & Diphenhydramine & 6 & $0.002-0.894(0.0126)$ \\
\hline & Diphenidol & 1 & $1.148(-)$ \\
\hline & Ibuprophen & 1 & $0.830(-)$ \\
\hline & Ketamine & 1 & $0.957(-)$ \\
\hline & Lidocaine & 37 & $0.020-7.709(0.422)$ \\
\hline & Methylephedrine & 2 & $0.020-0.078(0.049)$ \\
\hline & Propofol & 1 & $0.144(-)$ \\
\hline & Salicylic acid & 1 & $0.650(-)$ \\
\hline & Thiamylal & 2 & $0.452-15.494(7.973)$ \\
\hline
\end{tabular}


Table 3. PRL and DA levels in serum and CSF regarding classifications of detected drugs, respectively.

\begin{tabular}{|c|c|c|c|c|c|c|c|c|}
\hline \multirow{2}{*}{ Classifications of the detected drugs } & \multicolumn{4}{|c|}{ Prolactin levels (ng/mL) } & \multicolumn{4}{|c|}{ Dopamine levels (pg/ml) } \\
\hline & Serum & (median) & CSF & (median) & Serum & (median) & CSF & (median) \\
\hline Dopamine antagonists & $18.8-200$ & $(41.0)$ & $11.7-394$ & $(34.1)$ & $5-7190$ & $(2187.5)$ & $1100-63185$ & $(10500)$ \\
\hline Stimulants & $3.70-37.2$ & $(9.14)$ & $1.67-43.9$ & $(25.3)$ & $5-5497$ & $(1346)$ & $5-69913$ & (9416) \\
\hline $\begin{array}{l}\text { Psychotropic drugs } \\
\text { except for dopamine antagonists }\end{array}$ & $2.94-217$ & $(22.4)$ & $3.01-97.2$ & $(12.0)$ & $4-154565$ & $(717)$ & $5-191682$ & $(6588)$ \\
\hline Other non-psychotropic drugs & $1.99-49.4$ & $(24.3)$ & $1.49-51.3$ & $(14.5)$ & $5-1582899$ & $(1561.5)$ & $5-146149($ & $(13358.5)$ \\
\hline No detected drugs & $2.89-162$ & $(20.2)$ & $1.23-74.2$ & $(7.17)$ & $5-46899$ & $(185)$ & $5-70710$ & $(5870)$ \\
\hline Total & $2.89-217$ & $(22.2)$ & $1.23-394$ & $(10.9)$ & $4-1582899$ & $(616)$ & $5-191682$ & (7332) \\
\hline
\end{tabular}

